\title{
Hans Willener feierte seinen fünfundneunzigsten Geburtstag
}

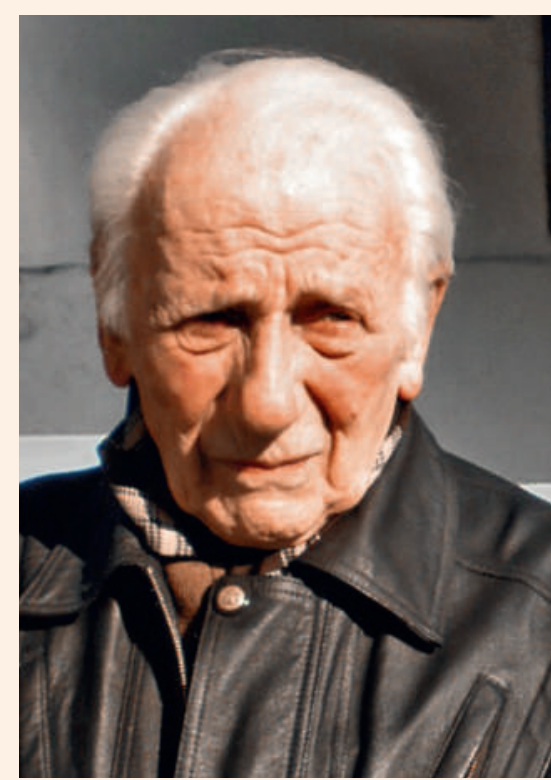

Dr. med. Hans Willener wurde am 28. April 1917 geboren.
Am 28. April konnte Dr. med. Hans Willener in seinem Alterssitz in Thal ob Erlenbach seinen fünfundneunzigsten Geburtstag feiern. Als Sohn des praktizierenden Arztes Gustav Willener, der zugleich als Spitalarzt wirkte, und der Mutter Marie, geborene Abbühl, die Lehrerin und ausgebildete Sängerin war, wuchs er bis zu seinem vierzehnten Lebensjahr mit drei Schwestern im elterlichen Wohnhause in Erlenbach auf. 1931 trat er in die Literarabteilung des Städtischen Gymnasiums Bern ein, und zwar in die griechische Klasse, die damals noch gleich gross war wie die beiden Parallelklassen, während heute Griechisch fast vergessen $\mathrm{zu}$ sein scheint. Nach erfolgreicher Matura bestand er die Aufnahmeprüfung zum Medizinstudium in Lausanne, denn gut französisch zu sprechen, galt als selbstverständlich für einen angehenden Akademiker.

Das weitere Studium der Medizin bis zum Staatsexamen im Jahre 1941 führte ihn nach Bern. Während des Studiums fanden ständig bereichernde Gespräche mit dem Vater statt, der eine beispielgebende objektwissenschaftliche Einstellung zur Medizin und eine umfassende Anteilnahme am Schicksal der Patienten hatte. Weitere medizinische Studien folgten für Innere Medizin, praktische Medizin und später Neurologie und Tropenmedizin. Nach dem Tod seines Vaters musste der junge Arzt bereits 1943 formell die Verantwortung für die Tuberkulose-Abteilung und die Innere Medizin am Bezirksspital Niedersimmental sowie die Praxis des Vaters übernehmen. Dabei musste er sich während der Mobilisation der Armee öfters wegen Aktivdienstes vertreten lassen. Zehn Jahre später kündigte er seine Stelle als Spitalarzt und gab seine Privatpraxis auf, obwohl sich alles gut angelassen hatte.

Nach einem Amt als Gemeinderat in Erlenbach verzichtete er auf weitere politische Tätigkeit, nicht zuletzt darum, weil sein geliebtes Klavier vermutlich dann zu kurz gekommen wäre. Zwei andere Leben gingen tiefgründig mit seinem Leben als Arzt einher: die Sorge um seine Familie, die ihn Tag und
Nacht begleitete und - fast als Nebenberuf - die Musik. So wie ihm sein Vater die Medizin, so lebte ihm seine Mutter die Musik vor. Von Jugend auf war er ihr Gesangsbegleiter und lernte dadurch die ganze klassisch-romantische Vokalliteratur kennen. Dank ihr wurde ihm sowohl als Klavierspieler wie als Organist Johann Sebastian Bach zum zentralen Komponisten. Herrlich in Erinnerung bleibt ihm auch stets das Zusammenspiel in Ensembles mit hochmusikalischen Menschen.

Wie sein Vater war auch Hans Willener schon in jungen Jahren ein Anti-Nazi und wurde während der Zeit des Dritten Reiches von 1933 bis 1945 von der Befürchtung eines Angriffs auf unser Land geprägt; deshalb wurde er Mitglied einer Geheimorganisation zur Förderung des eidgenössischen Widerstandswillens und zur Ausarbeitung politischer Stellungnahmen. Diese sogennannte Eidgenössische Gemeinschaft wurde nach dem Krieg ausführlich im Schweizer Fernsehen dargestellt. Sein Vater hatte schon von Anfang an das Hitlersche Terrorregime durchschaut und sich entsprechend verhalten.

Nach seinem Wegzug aus Erlenbach war er für verschiedene Missionen tätig: 1953, am Ende des Koreakrieges, war er dort Chef der schweizerischen Ärztemission, dann Delegierter des Internationalen Komitees vom Roten Kreuz in Algerien, wo der Befreiungskrieg zur Loslösung von Frankreich tobte, und schliesslich im Jahre 1956 Leiter der ersten Rotkreuzhilfskolonne in Ungarn, das sich damals gegen das kommunistische Diktat aus Moskau auflehnte. Nach dem Ungarnaufstand, der blutig niedergeschlagen wurde, betrieb der Jubilar in Payerne eine Privatpraxis und zuletzt in Bern eine Gemeinschaftspraxis mit dem Chirurgen Dr. Hans Kipfer, dem Sohn des berühmten «Kuechli-Kipfer». Diese Gemeinschaft war damals beispielgebend für die Organisation nützlicher Zusammenarbeit unter Ärzten.

Wie er selber sagt, hat ihm das Alter keine Lösung der Welträtsel beschieden, aber dafür einiges Misstrauen gegen Kraftmeierei in der Politik sowie hinterhältige Herrschaft des Mammons, mystisch schöne «Worterei» in der Heilkunde, armseligen Trost durch selbstgefällige Heils- und Gesundheitsverkünder. Seine Verehrung gehört der Poesie und der Naturkunde. 